\title{
Information Literacy Instruction in Asynchronous Online Courses: Which Approaches Work Best?
}

\section{Elizabeth Pickard and Sarah Sterling}

\begin{abstract}
Which modes of information literacy instruction (ILI) work best in asynchronous online courses? Recent national trends and COVID-19 have made it critical to answer this question, but there is little research comparing different modes of ILI specifically in asynchronous contexts. This multiyear study employed five different modes of ILI in different sections of an asynchronous online anthropology course and compared the modes' effects on students' coursework. Ethnographic analysis of students' bibliographies revealed nuanced changes to students' approaches to searching and source selection. These findings can inform librarians' development of ILI curricula and pedagogy for the unique circumstances asynchronous instruction presents.
\end{abstract}

\section{Introduction}

During the last decade, colleges and universities have offered an increasing number of courses online, presenting librarians with the challenge of providing course-integrated information literacy instruction (ILI) in both asynchronous and synchronous online-only courses. As reported by the Babson Survey Research Group (2018), enrollment in online courses by undergraduate students increased for the 14th consecutive year in the United States, ${ }^{1}$ and a 2019 National Center for Education Statistics report showed that college and university online enrollments continued to grow even as overall enrollment numbers declined. ${ }^{2}$ For example, Portland State University, a large R2 public university in Portland, Oregon, has offered an increasing number of online courses every year for the past several years and offered 65 percent of its courses as online-only in the 2016-2017 academic year. ${ }^{3}$ The COVID-19 pandemic made the need to move online even more urgent, and that intensified an already pressing question for librarians: which approaches to teaching information literacy work best in an online-only context? Moreover, which modes work best in asynchronous as opposed to synchronous courses?

Librarians need best practices now, and there are many things to consider. Colleen Flaherty, who covers faculty issues for Inside Higher Ed, explained in a recent, post-quarantine article that "synchronous is hot" but equity is a concern. ${ }^{4}$ Phil Hill, an ed-tech consultant at MindWires, told Flaherty, "The limitations of synchronous video are equity and access." ${ }^{5}$ While not entirely different, synchronous and asynchronous courses do involve some fundamental infrastructural differences that affect what modes of instruction might be possible. Synchronous courses allow

\footnotetext{
*Elizabeth Pickard is Assistant Professor and Science \& Social Sciences Librarian at Portland State University, email:epickard@pdx.edu; Sarah Sterling is Assistant Professor of Anthropology and Affiliate Faculty to the Middle Eastern Studies Center at Portland State University, email: sster@pdx.edu. (02022 Elizabeth Pickard and Sarah Sterling, Attribution-NonCommercial (https://creativecommons.org/licenses/by-nc/4.0/) CC BY-NC.
} 
for real-time interaction between instructor and students, and this real-time interaction readily facilitates active learning. Asynchronous learning, in contrast, is particularly student-centered with respect to flexibility, but the lack of real-time interaction begs the question of how one might go about facilitating active learning. There are many asynchronous online tools available, such as LibGuides and software to create video-recorded lectures, but how might librarians best use these tools to engage students in active learning rather than passive listening?

This article reports on a series of case studies from Portland State University (PSU) that compared different modes of delivering ILI in an asynchronous course and their effects on students' coursework. The researchers, a librarian and an anthropology instructor, tried five different modes of delivering ILI in different sections of the instructor's asynchronous online course and reviewed students' final project bibliographies to see in what ways the students' work had changed. Comparison of students' work under different modes of ILI revealed changes to the ways in which students had approached searching and supporting their topics as well as changes to the quality of their sources.

\section{Literature Review}

This research study examined the effects of different modes of ILI on students' coursework, focusing on modes that facilitate active learning. It specifically builds on existing research pertaining to ILI in asynchronous, as opposed to synchronous, online instruction.

Most existing literature talks about ILI in online courses without differentiating between synchronous and asynchronous instruction. This distinction is important since synchronous courses allow for different modes of ILI relative to asynchronous courses; synchronous courses allow for real-time interaction, while asynchronous courses are more accessible to a wider range of students but with limited real-time interaction (if any). ${ }^{6}$ Yet much of the literature discusses "online" as a blanket term. For example, in a 2010 article, Hoffman and Ramin proposed a set of best practices for interacting with online students, but they discussed "online" without specifying potential differences between asynchronous and synchronous contexts in either the project's systematic review or case study. ${ }^{7}$ It was only through Hoffman's mention of "web-conferencing" 8 that the researchers inferred that the case study most likely examined a synchronous course. This omission points to the fact that the use of asynchronous instruction, and especially literature on it, is still emerging. Even more recent articles, such as "Online Students' Perceptions of Embedded Librarians" ${ }^{\prime 9}$ and "Authentic Assessment of Student Learning in an Online Class," ${ }^{10}$ use the term "online" broadly. In "Online Students' Perceptions...," Spangler et al. disseminated a survey to students that did not appear to have asked, specifically, whether the online course the participating student had attended had been synchronous or asynchronous. ${ }^{11}$ Thus, the results documenting students' online course experiences with embedded librarians do not reflect that important granularity. In "Authentic Assessment of Student Learning," Alverson et al., who made use of a methodology similar to the one on which this article reports, also evaluates the effect of an embedded librarian in an online course ${ }^{12}$ without specifying whether the course itself was synchronous or asynchronous. Alverson made use of both synchronous and asynchronous modes of ILI, but it was unclear how the format of the course might have affected the outcomes. Neither recent study discussed the findings or recommended applications in terms of how they might apply differently to synchronous versus asynchronous course contexts.

The literature that does specifically discuss asynchronous ILI falls into two categories. Either these studies examined only one mode of delivering ILI in an asynchronous course, 
or their methods involved indirect rather than direct collection of data or measured affective rather than cognitive outcomes.

A few studies looked at the effects of a single mode of delivering ILI, and most of these focused on some mode of providing ILI using digital learning objects, such as videos, tutorials, and/or asynchronous online exercises. In "If We Built It, Would They Come," Camacho looked at the use of video tutorials with an accompanying quiz. ${ }^{13}$ In "Scalable Equals Asynchronous, and Asynchronous Equals Boring," Thompson and Carrier looked at a combination of Guide on the Side instruction and exercises and short videos, ${ }^{14}$ and in "Developing Online Instruction According to Best Practices," Lierman and Santiago piloted a series of recorded "lessons" and accompanying exercises for librarians to use. ${ }^{15}$ As these studies show, the term "digital learning objects" can refer to different things. Common characteristics among the objects these studies employed included that they all allowed for predelivery construction, repeated use without much additional work, and delivery to students in the absence of the librarian. While there were a variety of ways digital learning objects delivered ILI among these studies, none of the studies compared different modes of ILI for asynchronous course contexts. Each study only explored the one mode the researchers for that study had delivered.

It is significant that all of these studies examined ILI that facilitated active learning. In 1999, Nancy Dewald wrote two articles "Transporting Good Library Instruction Practices into the Web Environment," and "Information Literacy at a Distance," in which she asserts that Web tutorials must be interactive to facilitate active learning and, thus, reinforcement of the information presented. ${ }^{16}$ That time seems long ago, but higher education had actually embraced active learning well before 1999, beginning with the work of educational reformer John Dewey, whose ideas shifted pedagogical methods away from emphasizing the idea of students as passive vessels toward emphasizing problem- and project-based learning. ${ }^{17}$ Likewise, the current model of Bloom's Taxonomy of Education Objectives ${ }^{18}$ focuses largely on activities that support learning; thus, it plays an important role in the development of outcomes for active course curricula. Bloom's Taxonomy places class activities that ask students to simply listen in order to remember or recite back information among the lowest levels of learning. The ACRL Framework for Information Literacy, which was intended to guide ILI development by "librarians, faculty, and other institutional partners in their design of instruction sessions, assignments, courses, and even curricula"19 targets higher-order concepts in keeping with Bloom's.

While literature in online ILI uses the phrase "active learning" in a variety of ways, it consistently holds forth the ideal of facilitating student engagement rather than passive listening. Lierman notes that Dewald "seems to use the term [active learning] interchangeably with 'interactivity'," ${ }^{20}$ while, in "Online Active Learning," Parramore goes on to say that simply including quizzes, tutorials, practice questions, and assessments in online ILI is not enough. "[M]erely including them into an online-environment does not qualify it as completely active learning." ${ }^{21}$ She suggests that online ILI needs to be delivered to students in keeping with the thinking of Anastasia Misseyanni ${ }^{22}$ and Lorayne Robertson ${ }^{23}$ in Active Learning Strategies in Higher Education, such that the ILI "engages the student with meaningful learning activities and allows a metacognitive process to take place where students become active contributors to the class." ${ }^{24}$ Robertson emphasizes metacognition as "a critical skill that enables students to assess their own learning and also critically assess sources of information," ${ }^{25}$ which harkens back to Dewey's project-based learning. 
The methods employed by many of the online ILI studies did not measure outcomes relating to metacognition. In a recent article outlining differences among and implications for IL assessment practices, William Walters discusses assessing cognitive versus affirmative outcomes and how using direct versus indirect methods to collect data affects that measurement. ${ }^{26}$ Walters asserts that "the distinction between evidence-based and perception-based measures is nearly identical to the distinction between cognitive and affective measures." ${ }^{27}$ Cognitive, or evidence-based, measures look at data in which students demonstrate their skills as opposed to affective measures that examine students' confidence (for example) using those skills. Of indirect versus direct methods of data collection--which Walters says "are closely linked to cognitive or affective constructs" 28 -Walters explains that indirect methods, such as surveys or self-evaluations, in which students report what they do, build in a level of abstraction that introduces bias. ${ }^{29}$ Direct methods involve researchers looking "directly" at the data about which they are making claims (for example, looking at students' actual coursework rather than looking at what students say about having produced it). Camacho looked at how many students had watched an ILI video but did not measure how much students understood of what they had seen. ${ }^{30}$ Thompson measured students' understanding indirectly, by looking at answers to "formative questions" that were part of the ILI tutorial. ${ }^{31}$ Lierman used direct methods to measure cognitive outcomes by working with instructors to look at students' coursework after completing online-only ILI lessons, but the pilot involved a small sample size..$^{32}$ Alverson et al., however, looked at a larger sample of bibliographies that students produced as part of their college Research Seminar final projects. ${ }^{33}$ While Alverson did not necessarily look at an asynchronous course and only examined results of one mode of ILI (embedded librarian), her study is the closest in methodology to the one on which this article reports because students' coursework serves as the data. Walters states, "[T] he evaluation of students' written [course]work - the direct, authentic assessment of cognitive outcomes - is the single most useful IL assessment exercise." ${ }^{34}$

Citation analysis has long been used as a direct method of assessing cognitive outcomes of ILI. Bonnie Gratch (1985) claimed that research paper bibliographies reflect the effects of "research skills instruction." ${ }^{35}$ Since Gratch's early work, numerous researchers have analyzed citations with this idea in mind, usually analyzing the quality of the sources but defining "quality" in many different ways. Past citation analysis studies have looked at criteria such as scholarliness, ${ }^{36}$ authority of sources, ${ }^{37}$ number of sources,${ }^{38}$ variety among sources, ${ }^{39}$ format (journals, books, newspapers, websites, and so on), ${ }^{40}$ citation style formatting, ${ }^{41}$ appropriateness with respect to the topic, ${ }^{42}$ and dates and currency. ${ }^{43}$ In "A Faceted Taxonomy for Rating Student Bibliographies," Leeder, Markey, and Yakel noted of such past citation analysis studies that the "...definitions of terms are not standard and vary from study to study." ${ }^{44}$ More recently, Dahlen and Hansen tried to address this variation by using the term "quality," as a more flexible option than "authority." 45

However, even the studies using the term "quality" approached analysis using a preset rubric to measure outcomes, including Alverson's work on ILI in online courses. ${ }^{46}$ These studies' methodologies did not allow for the discovery of unanticipated effects of ILI on students' bibliographies or discovery of unexpected subtle and meaningful changes. The study on which this article reports employs citation analysis but approached evaluation of a source's quality differently from existing studies. Instead of measuring outcomes by presupposed standards, the current study asked, as the basis of evaluation, "Which aspects of bibliographies changed under different modes of ILI and in what ways did they change?" 
The current study used citation analysis to directly measure and compare the cognitive outcomes of five different modes of ILI delivered in seven sections of an asynchronous online course. The study examined only modes of ILI that facilitated active learning. Unlike prior studies, this study focused on asynchronous courses and was able to compare the effects of multiple different modes of providing ILI, including two that had not yet been studied in asynchronous contexts; ILI via curriculum scaffolding only in which research skills exercises and instruction were built into existing course assignments, and ILI via a live one-shot session. The study also adds to the existing literature findings from exploratory modes of analysis that allowed for discovery of unanticipated and nuanced effects of ILI on students' selection of sources.

\section{Methodology}

In this comparative series of case studies, a librarian and an anthropology instructor designed and employed five different modes of ILI in the instructor's asynchronous online courses-Anthropology 366: Archaeology of Mesoamerica and Anthropology 368: Archaeology of Oceania. The researchers then coded students' final project bibliographies from these courses to explore the ways in which the bibliographies had changed in response to the different modes of ILI. From this coding, themes emerged about changes to students' approaches to searching for sources and supporting their topics and changes to the quality of the sources they selected.

With IRB approval, the researchers recruited students via email. Interested students uploaded a consent form and their final research projects to the course Desire to Learn (D2L) shell. Participating students received a \$10 Amazon gift card.

\section{Modes of ILI}

The researchers looked at the bibliographies of students from two courses: ANTH 366 (Archaeology of Mesoamerica) and ANTH 368 (Archaeology of Oceania). The researchers considered these courses equivalent because both courses have the same fundamental structure:

- They are taught by the same instructor.

- They are at the same level.

- They have the same prerequisites.

- They are both asynchronous.

- They involve the same assignments: two reading reviews and a final research project, and the assignments from each course have the same essential structures (see appendix A).

The researchers employed and examined different modes of delivering ILI each term via D2L (PSU's online learning management system). The researchers started by seeking a baseline sense of students' research skills as the instructor had traditionally taught them, which involved no supplemental ILI. The researchers went on to look at modes of ILI that involved the following: 1) curriculum scaffolding only, consisting solely of changes to the assignments and no supplemental library involvement; 2) an embedded librarian, which consisted of intensive involvement by the librarian; 3) more sustainable ILI in a term consisting of a synchronous ILI session that aimed to provide the active learning facilitated by traditional "one-shot" sessions in face-to-face courses; and 4) a term involving digital learning objects that consisted of a series of videos and graded exercises (see figure 1). 


\begin{tabular}{|c|c|}
\hline \multicolumn{2}{|c|}{$\begin{array}{c}\text { FIGURE } 1 \\
\text { Modes of ILI by Term: Sample Sizes }\end{array}$} \\
\hline Mode of ILI & Sample Size \\
\hline $\begin{array}{r}\text { TAUGHT AS USUAL } \\
\text { ANTH } 366 \& 368 \\
\text { Spring } 2016\end{array}$ & $\begin{array}{l}\text { ANTH 366: } 26 \text { of } 32 \text { (81\%) bibliographies } \\
\text { ANTH 368: } 23 \text { of } 30 \text { (77\%) bibliographies } \\
49 \text { students cited a total of } 123 \text { sources }\end{array}$ \\
\hline $\begin{array}{r}\text { CURRICULUM SCAFFOLDING ONLY } \\
\text { ANTH } 366 \& 368 \\
\text { Fall } 2016\end{array}$ & $\begin{array}{l}\text { ANTH 366: } 30 \text { of } 33 \text { (91\%) bibliographies } \\
\text { ANTH 368: } 25 \text { of } 29 \text { (86\%) bibliographies } \\
55 \text { students cited a total of } 266 \text { sources }\end{array}$ \\
\hline $\begin{array}{r}\text { EMBEDDED LIBRARIAN } \\
\text { ANTH } 366 \\
\text { Winter } 2017\end{array}$ & $\begin{array}{l}25 \text { of } 30(83.3 \%) \text { bibliographies } \\
25 \text { students cited a total of } 124 \text { sources } \\
\text { (ANTH } 368 \text { was cancelled) }\end{array}$ \\
\hline $\begin{array}{r}\text { SYNCHRONOUS ILI SESSION } \\
\text { ANTH } 366 \\
\text { Fall } 2017\end{array}$ & 21 of 25 (84.0\%) bibliographies citing 99 total sources \\
\hline $\begin{array}{r}\text { DIGITAL LEARNING OBJECTS ONLY } \\
\text { ANTH } 368 \\
\text { Fall } 2017\end{array}$ & 24 of $28(85.7 \%)$ bibliographies citing 129 total sources \\
\hline
\end{tabular}

\section{Analysis}

Analysis of students' final project bibliographies involved looking at the effects of specific modes of ILI on the quality of individual sources selected and on the quality of the bibliographies in their entirety. The researchers approached evaluating the "quality" of the bibliographies and individual sources inductively to unearth unexpected and nuanced changes. Drawing on Barney Glaser's seminal work on qualitative analysis, researchers first coded the sources to get at "the interrelationship between meaning in the perception of the subjects and their action." 47 The researchers noted which areas of the bibliographies changed between terms, what about those areas had changed, and what these changes suggested about students' engagement with the research process, evaluation of sources, and supporting their topics. In this way, the researchers' approach to analysis was what Glaser refers to as "controlled by the emerging theory." 48 Such ethnographic methods help identify discrepancies between what people intend to do and what they actually do, and these methods help unearth unexpected behaviors and correlations. In the article, "Ethnography as Theory," Laura Nader calls ethnographic writing necessarily "a theory of description." ${ }^{49}$ Similarly, Anthony Kwame Harrison explains in the "Writing up Research Findings" chapter of his book, Ethnography, "in the most essential sense, ethnography is produced via writing." 50 This is necessary to describe "not only what takes place but also how it occurs." 51 Thus, in this article, the researchers describe the ligaments they see connecting findings as a way of facilitating transparency.

The researchers approached developing the rubric for the instructor's evaluation of students' sources in a similar way. The instructor used her subject-expertise to analyze students' sources and label them "too basic," "standard," or "advanced," based on how specific and significant a source was to the student's topic and how appropriate the source was for the course level. The rubric for her final analysis grew out of the data. The instructor first coded students' sources to see which ones she would expect to see for the course topic and level, which ones seemed less able to support the student's topic, and which sources surprised her 
as doing more to support the student's topic than she would have expected for the course level. From the instructor's coding, more specific themes emerged that the researchers then developed into a rubric, the Instructor's Source-Evaluation Index. The final Index defined the categories, "too basic," "standard," and "advanced," in more nuanced ways. To make sure the researchers had evaluated the citations according to consistent standards, the instructor coded the sources again (normed) using the final parameters of the Index.

Allowing the themes and rubrics to emerge out of the data facilitated a particularly nuanced analysis of students' bibliographies, especially with respect to the instructor's expectations, that allowed researchers to build upon Alverson's work on embedded librarians in online courses. ${ }^{52}$ This approach also allowed researchers to unearth granular differences in students' work in response to the different modes of ILI students had received.

\section{Broader Goals}

The broader goal of this study was to contribute to the development of best practices for delivering ILI in online-only courses. Toward this end, the specific goals were to explore the effects of different modes of ILI on students' coursework with respect to the following: 1) students' ability to find reliable sources; 2) students' understanding of the research landscape (such as range of databases and types of sources); and 3) students' understanding of research as a process.

\section{Key Findings}

The study looked at specific aspects of citations and bibliographies to assess quality in addition to considering citations and bibliographies with the idea that they might change in unanticipated ways in the context of different modes of ILI. This approach allowed the researchers to unearth unexpected and nuanced results of the different modes of ILI, such as changes to how well students' sources supported their research topics, changes to the breadth of students' use of databases, and - without the final assignment changing its requirements-changes to the length of students' bibliographies. Two broader findings that framed other results were that intentional, substantial curriculum scaffolding can provide some effective ILI but that more dedicated, formal ILI can do additional important work. The findings also concluded that the most effective mode of dedicated ILI, "embedded librarian," was not sustainable for the librarian. The researchers went on to explore two more sustainable modes of ILI with the intent to achieve the same effectiveness as the embedded librarian mode.

\section{From No Intervention to Intensive Intervention}

The researchers approached the first three terms of the study by establishing a baseline term and then comparing it to a term involving minimal involvement by the librarian and a term involving intensive involvement by the librarian. The researchers approached Spring 2016 by establishing baseline examples of students' work from the course as the instructor had traditionally taught it with minimal supplemental library instruction (see figure 2). The ILI this term existed incidentally, as exposure to the library via links to required readings and mentions of the library in final project guidelines (see appendix A). The two reading reviews (each worth 25 points) included direct access to the required reading for the assignment through links in D2L and did not require students to find the sources themselves. Likewise, the final project assignment (worth 65 points) did not specify the number of sources that students should use, nor did it direct students to particular databases. 


\begin{tabular}{|c|c|c|}
\hline \multicolumn{3}{|c|}{$\begin{array}{l}\text { FIGURE } 2 \\
\text { Modes of ILI: No Intervention to Intensive Intervention } \\
\text { (activities in bold are new for that term) }\end{array}$} \\
\hline $\begin{array}{l}\text { TAUGHT AS USUAL } \\
\text { ANTH } 366 \& 368 \\
\text { Spring } 2016\end{array}$ & $\begin{array}{c}\text { CURRICULUM SCAFFOLDING ONLY } \\
\text { ANTH } 366 \& 368 \\
\text { Fall } 2016\end{array}$ & $\begin{array}{c}\text { EMBEDDED LIBRARIAN } \\
\text { ANTH } 366 \\
\text { Winter } 2017\end{array}$ \\
\hline $\begin{array}{l}\text { Reading review 1: } \\
\text { link to reading }\end{array}$ & $\begin{array}{l}\text { Reading review 1: } \\
\text { - Citation only for reading } \\
\text { - Find more recent article } \\
\text { - Librarian Q\&A area on D2L wiki } \\
\text { (not required) }\end{array}$ & $\begin{array}{l}\text { Reading review } 1 \text { : } \\
\text { - Citation only for reading } \\
\text { - Find more recent article } \\
\text { - Required to ask librarian a question } \\
\text { (email/D2L) }\end{array}$ \\
\hline $\begin{array}{l}\text { Reading review 2: } \\
\text { link to reading }\end{array}$ & $\begin{array}{l}\text { Reading review 2: } \\
\text { - Citation only for reading } \\
\text { - Find more recent article } \\
\text { - Librarian Q\&A area on D2L wiki } \\
\text { (not required) }\end{array}$ & $\begin{array}{l}\text { Reading review } 2 \text { : } \\
\text { - Citation only for reading } \\
\text { - Find more recent article } \\
\text { - Required to ask librarian a question } \\
\text { (email/D2L) }\end{array}$ \\
\hline Final research project & $\begin{array}{l}\text { Preliminary bibliography due } \\
\text { before final project }\end{array}$ & $\begin{array}{l}\text { Preliminary bibliography due before } \\
\text { final project }\end{array}$ \\
\hline
\end{tabular}

Four changes were implemented in Fall 2016 to see how curricular scaffolding, without any formal instruction by a librarian, might affect the quality of students' research. The researchers kept the reading review assignments the same except to provide a citation for, rather than a link to, the assigned readings and require students to find on their own an additional, more current article on the reading review topic. Third, the researchers also added an entirely new preliminary bibliography assignment (see appendix B) to prepare students for the final project (which, otherwise, stayed the same). The preliminary bibliography was due three weeks before the final research project, was worth 15 points, and required students to find three sources. Fourth, the librarian was available via a dedicated research discussion wiki in D2L for any questions that students had about finding sources.

The researchers speculated that giving students practice using these research tools and skills earlier in the term might lead to their developing better bibliographies. In other words, the researchers hoped to open up time for students to evaluate sources and employ iterative, rather than desperate, searching by obviating students having to figure out what research tools were available to them, how to use those tools, how to get the full text of sources into their possession, and how to evaluate those sources at the same juncture they were trying to learn about a new topic, write the body/narrative of the research project, and generally complete a larger research project.

For Winter 2017, researchers included the assignments and curriculum scaffolding deployed in Fall 2016 and added more dedicated, formal ILI in the form of two required reference encounters for each student. Both reading review assignments required students to ask the librarian a question about finding sources for the assignment.

The reading review instructions included a 5-of-25-point requirement that students contact "...our embedded librarian, Elizabeth, to identify one reference that updates, or builds on the information in this reading. The reference can relate to any part of the reading and should be from the library's holdings." Students could either post their question to a dedicated D2L discussion thread or email the librarian directly. Students' questions were 
vetted by instructor and librarian so it was clear to students they would not get 5 points for asking perfunctory questions such as, "Can you help me?" When such questions occurred, the librarian prompted students by email (copying the instructor) with the follow-up question, "Are you having trouble using databases, developing search terms, or getting to the full text?" Copying the instructor made it clear that students would not get the 5 points without responding with a more detailed question. Depending on the student's more detailed question, the librarian then asked, "Where have you tried searching?" "Which search terms have you tried so far?" or "Through what database did you try to get the full text?" The researchers intended these prompts to lay out expectations for students about what the research process entails and to encourage students to do some searching before asking. The librarian made a point in communication with every student to point to the archaeology subject guide, recommend at least two specific databases based on the student's topic, and to recommend a range of search terms to try.

The embedded librarian mode resulted in students developing particularly substantial bibliographies, reduced the workload for the instructor, and allowed the instructor to focus on discussing archaeology rather than finding sources. However, the workload was not sustainable for the librarian. The instructor reported that her conversations with students focused almost entirely on the discipline of archaeology during the "embedded librarian" term and that less discussion about finding sources actually meant less work for her overall. (She also reported a reduction in students' end-of-term panic as well as her own.) However, the "embedded librarian" ILI involved 10 to 40 hours of work per week for the librarian for one class, and, like many other librarians, she teaches many classes for multiple departments. Thus, the question for the researchers became how to achieve comparable results via a mode of ILI that would be sustainable for librarians. The next term of the study explored two options.

\section{Experiments in Sustainable ILI}

During the final term of the study, researchers tried two different modes of ILI that aimed for the results of the "embedded librarian" mode but involved a sustainable workload for the librarian: a mode in a section of ANTH 366 that involved synchronous librarian interaction with students (in an otherwise asynchronous course), and a mode in a section of ANTH 368 that involved only asynchronous digital learning objects. The modes of ILI researchers employed this term were intended to obviate two of the more time-consuming aspects of the "embedded librarian" term (Winter 2017), namely, repeating the same information to every student in the course and contacting each student individually.

Building on prior effective terms of the study, both modes of ILI involved scaffolding research skills in assignments across the course term using the same assignment structure and schedule as the prior "curriculum scaffolding" and "embedded librarian" terms (see figure 3); specifically, the reading review assignments continued to provide a citation for the required readings and to require students to find an additional source on the topic, and students still had to complete a preliminary bibliography a few weeks before the final project deadline that required students to find three sources. As with the "curriculum scaffolding" and "embedded librarian" terms, the aim was to give students practice using databases throughout the term and to make students accountable for this work.

The only thing that changed in the assignments this term was the form of contact students were required to have with the librarian. In alignment with the promising results from 


\begin{tabular}{|c|c|}
\hline \multicolumn{2}{|c|}{$\begin{array}{l}\text { FIGURE } 3 \\
\text { Modes of ILI: Experiments in Sustainable ILI (activities in bold are new for that term) }\end{array}$} \\
\hline $\begin{array}{c}\text { SYNCHRONOUS ILI SESSION } \\
\text { ANTH } 366 \\
\text { Fall } 2017 \\
\end{array}$ & $\begin{array}{c}\text { DIGITAL LEARNING OBJECTS ONLY } \\
\text { ANTH } 368 \\
\text { Fall } 2017 \\
\end{array}$ \\
\hline $\begin{array}{l}\text { Reading review } 1 \\
\text { - Citation only for reading } \\
\text { - Find more recent article } \\
\text { - Required live group video conference (via D2L) } \\
\text { with librarian }\end{array}$ & $\begin{array}{l}\text { Reading review } 1 \\
\text { - Citation only for reading } \\
\text { - Find more recent article } \\
\text { - DLOs \& graded quiz } \\
\text { - No librarian }\end{array}$ \\
\hline $\begin{array}{l}\text { Reading review } 2 \\
\text { - Citation only for reading } \\
\text { - Find more recent article }\end{array}$ & $\begin{array}{l}\text { Reading review } 2 \\
\text { - citation only for reading } \\
\text { - find more recent article } \\
\text { - No librarian }\end{array}$ \\
\hline Preliminary bibliography due before final project & Preliminary bibliography due before final project \\
\hline
\end{tabular}

the "embedded librarian" term, the ILI in both of these sections made a point of introducing students to the subject guide for archaeology and to specific databases to support their topics, explicitly discussing expectations of the research process, such as the fact that it would be iterative and involve exploring different databases and search terms, and making the ILI a graded assignment.

The modes of ILI in ANTH 366 this term required students to attend a real-time instruction session with the librarian via D2L. The librarian taught three different 45 -minute sessions, and students had to pick one to attend. The sessions took place in week 2 of the term so as to occur at the point-of-need for students working on the reading review assignment due week 3 . The instructor disseminated both assignments at the same time to suggest a connection between the two, and the final project guidelines also noted a connection, stating, "[Y]ou will receive instruction on using the library's online databases during week 2." Since the ILI session was graded separately from a larger assignment this term, the researchers made it worth 10 points rather than 5 to compel students to complete it. Of the 25 students in the class, $15(60.0 \%)$ attended the ILI session.

The mode of ILI in ANTH 368 this term required students to complete an online exercise that involved video tutorials and practice questions (see appendix C). As with the synchronous ILI session, the exercise was assigned in week 2 of the term so it would occur at the point-of-need for students working on the reading review assignment due week 3. This mode involved a substantial amount of preplanning: designing and creating the videos using Camtasia and MediaSpace and the exercise itself using Qualtrics. Unlike teaching a live session each term, all work occurred before the course began, and a time-saving benefit of this mode was that the librarian could use the object, with minimal additional work, to provide ILI in future sections of the course. The resulting exercise could also serve as a template for the librarian to use in other asynchronous classes as well. The upfront work was also somewhat offset by making use of the PSU Library's collection of "reusable" videos the PSU librarians regularly develop and share. Since the ILI exercise was graded separately from a larger assignment this term, the researchers made it worth 10 points rather than 5 to compel students to complete it. Of the 28 students in the course, 21 (75.0\%) completed the Qualtrics exercise. 


\section{Changes in Student Work}

Students' bibliographies changed significantly and in a variety of ways under these different modes of ILI, correlating with the intensity of the ILI students received. The primary aspects that changed were the length of the bibliographies and how well they met the instructor's expectations for the topic and course level. These changes also pointed to changes in students' understanding of the research process and in their search behavior as reflected by the databases they used.

\section{Length}

More intentional ILI led to students exceeding required minimum number of sources in their bibliographies (that is to say, students made decisions about how many sources to include based on something more than just meeting the required minimum number). In the "taught as usual" term, the final project instructions did not specify a required number of sources, and the mode number that term was one source (see figure 4). The "curriculum scaffolding" term introduced a new preliminary bibliography assignment that required students to find three sources, and the mode number that term increased to three sources, in keeping with the new required minimum.

What surprised researchers was that the "embedded librarian" term employed exactly the same assignments and source requirements as the "curriculum scaffolding" term, but the bibliographies in the "embedded librarian" term were longer. The mode number of sources per bibliography in the "embedded librarian" term was four sources, meaning most students in the "embedded librarian" term exceeded the required minimum of three sources. In fact, 16 of 25 students (64\%) that term cited four or more sources. Students in the embedded librarian class seemed to be making decisions about how many sources to cite based on something more than just the minimum required number.

This change in decision-making was prevalent under the more sustainable modes of ILI as well but was more prevalent in the "digital learning objects" section. The length of the bibliographies in both sections ranged from 1 to 11 sources, but the mode in the "digital learning objects" section was five sources while it was only three in the "synchronous ILI" section (see figure 4). Students in the "synchronous ILI" section still cited more sources than the required minimum three: the mode was three sources, but 57 percent of students exceeded the minimum, citing four

\begin{tabular}{|c|c|c|c|c|c|}
\hline \multicolumn{6}{|c|}{$\begin{array}{c}\text { FIGURE } 4 \\
\text { Number of Sources per Student/Bibliography }\end{array}$} \\
\hline & TAUGHT AS USUAL & $\begin{array}{l}\text { CURRICULUM } \\
\text { SCAFFOLDING }\end{array}$ & $\begin{array}{l}\text { EMBEDDED } \\
\text { LIBRARIAN }\end{array}$ & $\begin{array}{l}\text { DIGITAL LEARNING } \\
\text { OBJECTS }\end{array}$ & $\begin{array}{l}\text { SYNCHRONOUS } \\
\text { ILI SESSION }\end{array}$ \\
\hline Range & $1-8$ & $1-17$ & $2-15$ & $1-11$ & $1-11$ \\
\hline Mean & $\begin{array}{c}2.6 \\
\text { (2.2 ANTH 366; } \\
\text { 2.9 ANTH 368) }\end{array}$ & $\begin{array}{c}4.8 \\
\text { (4.8 ANTH 366; } \\
\text { 4.9 ANTH 368) }\end{array}$ & 5.0 & 5.4 & 4.7 \\
\hline Median & $\begin{array}{c}1 \\
\text { (2 ANTH 366; } \\
2 \text { ANTH 368) }\end{array}$ & $\begin{array}{c}4 \\
\text { (ANTH } 366 \& 368)\end{array}$ & 4 & 5 & 4 \\
\hline Mode & 1 (ANTH $366 \& 368)$ & $\begin{array}{c}3 \text { (ANTH } 366 \& \\
368)\end{array}$ & 4 & 5 & 3 \\
\hline
\end{tabular}


or more sources. In comparison in the "digital learning objects" section, the mode increased to five sources and 75 percent of students exceeded the minimum number of required sources, citing four or more. In fact, even more students in the "digital learning objects" section exceeded source number requirements than in the "embedded librarian" section (Winter 2017): 75 percent versus 64 percent. Thus, the "digital learning objects" mode of ILI this study employed seemed relatively effective in drawing students' attention to the significance of the bibliography.

The embedded librarian and digital learning objects modes of ILI employed in this study resulted in students paying particular attention to the bibliography portion of their research projects as demonstrated by their making decisions about how many sources to cite based on something more than just the minimum required number. This change in behavior from prior terms suggests that students in the "embedded librarian" and "digital learning objects" classes better understood the function of the bibliography and made decisions about how many sources to cite based on a desire to support their topic rather than to meet a minimum requirement. This idea is further supported by the instructor's assessment of students' sources.

\section{Instructor's Assessment of Students' Sources}

The instructor used her subject expertise to analyze students' sources according to the Instructor's Source-Evaluation Index, a rubric that grew out of the data. The instructor first coded students' sources with respect to what she would expect to see for the course topic and level. From this coding, specific themes emerged that the researchers then developed into a more nuanced rubric (see figure 5).

As happened with the number of sources students cited, findings suggest a correlation between more dedicated ILI and students' selection of sources that better supported their topics. These broad findings did not surprise the researchers, but what added nuance to their understanding of the effects of the different modes of ILI were the differences between the terms in the number of sources that fell into the "standard" and "advanced" categories.

\begin{tabular}{|c|c|c|c|}
\hline \multicolumn{4}{|c|}{$\begin{array}{c}\text { FIGURE } 5 \\
\text { Instructor's Source-Evaluation Index Rubric }\end{array}$} \\
\hline CATEGORY & Too Basic & Standard & Advanced \\
\hline Criteria & $\begin{array}{l}\text { The source: } \\
\text { - discussed the topic } \\
\text { broadly without } \\
\text { discussing specifics } \\
\text { (e.g., non-specialized } \\
\text { encyclopedia) } \\
\text { and/or } \\
\text { - did not verify claims } \\
\text { via data or confirmable } \\
\text { information } \\
\text { and/or } \\
\text { - was not written by a } \\
\text { qualified expert* }\end{array}$ & $\begin{array}{l}\text { The source: } \\
\text { - was written by an expert* } \\
\text { AND } \\
\text { - verified claims with data } \\
\text { or other confirmable } \\
\text { information } \\
\text { and/or } \\
\text { - was a peer-reviewed article } \\
\text { or website, depending on } \\
\text { the website (e.g., included } \\
\text { websites presenting grey } \\
\text { literature, ongoing research } \\
\text { by experts*, oral histories.) }\end{array}$ & $\begin{array}{l}\text { The source: } \\
\text { - met all criteria for "standard" } \\
\text { AND } \\
\text { - was significant vs. just relevant } \\
\text { and/or } \\
\text { - was written in technical or } \\
\text { specialized vernacular } \\
\text { and/or } \\
\text { - contained complex } \\
\text { archaeological concepts } \\
\text { and/or } \\
\text { - contained concepts from } \\
\text { another discipline students } \\
\text { abstracted to use in archaeology }\end{array}$ \\
\hline
\end{tabular}


The sources students chose during a term with dedicated ILI, namely, the "embedded librarian," "digital learning objects," and "synchronous ILI session" classes, better met the instructor's expectations (in other words, the sources fell into either the standard or advanced categories). However, the curriculum scaffolding the researchers employed also did some successful ILI work. The instructor's analysis showed an 11 percent increase (from $62 \%$ to $73 \%$ ) between the "taught as usual" and "curriculum scaffolding" terms and a corresponding 11 percent decrease in sources that were "too basic" (see figure 6). This 11 percent shift means that the curriculum scaffolding the researchers employed helped students better select sources that met the instructor's expectations.

However, while curriculum scaffolding did some work, dedicated ILI led to even larger increases in students' selection of sources that met the instructor's expectations. Of the sources that students in the "embedded librarian," "digital learning objects," and "synchronous ILI session" classes selected, the instructor ranked 85, 84, and 82 percent, respectively, as either standard or advanced compared to 73 percent in the "curriculum scaffolding" term.

Moreover, the instructor's analysis of students' sources showed particularly significant increases in students' selection of "advanced" sources in classes involving dedicated ILI. The instructor actually placed 29 percent more students' sources from the "embedded librarian" term in the advanced category than in the "curriculum scaffolding" term ( $37 \%$ vs. $8 \%)$, mean-

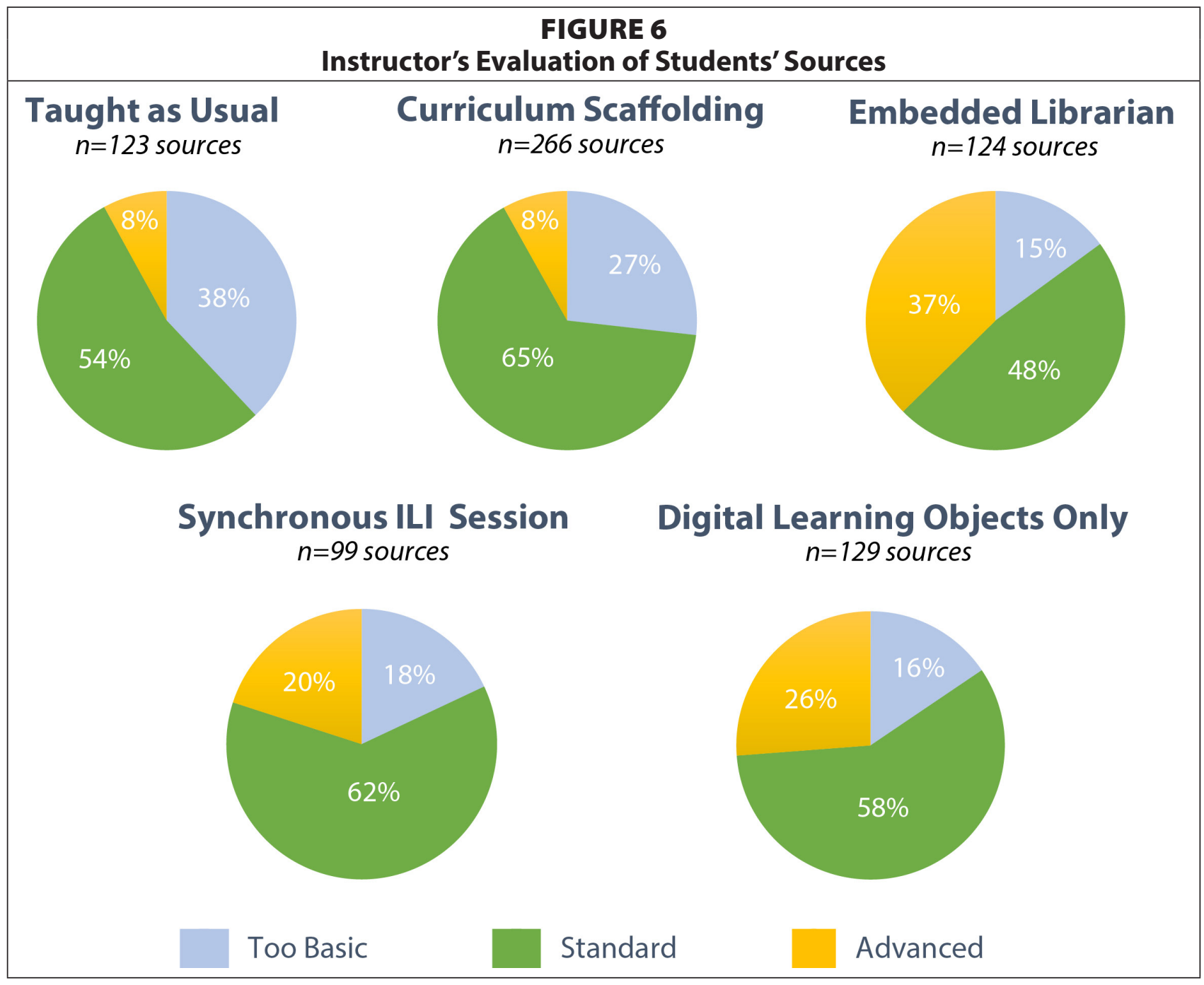


ing that among the sources that would satisfy the instructor's expectations, there was actually a substantial increase in the percentage of sources that would exceed her expectations.

The "digital learning objects" and "synchronous session" modes of ILI also led to students selecting more sources the instructor viewed as advanced than in terms without dedicated ILI. However, in both these terms, students selected fewer "advanced" sources than in the "embedded librarian" term. Of the sources students in the "digital learning objects" class selected, 26 percent fell into the "advanced" category, and in the "synchronous ILI session," 20 percent fell into the "advanced" category (see figure 6). Compared to 8 percent in the "curriculum scaffolding" term, 20 and 26 percent seem like a lot, but these numbers are markedly lower than the 37 percent of students' sources the instructor ranked as "advanced" in the "embedded librarian" term.

Students selecting "advanced" sources took on more intensive and specialized evaluation, or evaluation that involved an unexpected level of abstraction. This change in behavior suggests that students in terms with dedicated ILI had developed one or more of these attributes: 1) they were able to do this type of evaluation because they knew how and/or because they had more time to do it; and/or 2) they were aware of databases that provided such specialized sources; and/or 3) they were willing to include such sources because they better understood the important role sources play in supporting points made in their research projects.

\section{Breadth of Databases Students Used}

Students in the terms with dedicated ILI were the only ones to cite sources from the Web of Science and other specialized anthropology databases. If the librarian had provided dedicated ILI, as would happen in a face-to face course or one-on-one reference encounter, she would have pointed students in both ANTH 366 and ANTH 368 to specific databases: Web of Science (which was included in the federated search function of the library's discovery tool) and the specialized anthropology databases: Anthropology Plus, Anthropological Index, and AnthroSource (which were not included in the federated search function). She would also have pointed students to the archaeology subject guide (LibGuide) as another important place students should look for additional databases and resources.

The only terms in which students received such dedicated ILI were in the "embedded librarian," "digital learning objects," and "synchronous ILI session" terms, and these were the only terms in which students cited sources from Web of Science or from any of these specialized anthropology databases. Students citing Web of Science included 24 percent in the "embedded librarian" term, 8 percent in the "digital learning objects" term, and 5 percent in the "synchronous ILI" term, compared to 0 percent in the "taught as usual" and "curriculum scaffolding" terms (see figure 7). Likewise, in the more dedicated ILI terms, students cited spe-

\begin{tabular}{|l|c|c|c|}
\hline \multicolumn{4}{|c|}{ FIGURE 7 } \\
\hline & Web of Science & Anthropology Plus ${ }^{*}$ & AnthroSource* $^{*}$ \\
\hline Taught as Usual & 0 & 0 & 0 \\
\hline Curriculum Scaffolding Only & 0 & 0 & 0 \\
\hline Embedded Librarian & $6(24 \%)$ & $5(20 \%)$ & $2(8 \%)$ \\
\hline Digital Learning Objects & $2(8 \%)$ & $3(12 \%)$ & $1(4 \%)$ \\
\hline Synchronous ILI & $1(5 \%)$ & $1(5 \%)$ & $1(5 \%)$ \\
\hline${ }^{*}$ Not included in Library discovery tool federated search. \\
\hline
\end{tabular}


cialized anthropology databases not included in the library discovery tool's federated search: 28 percent in the "embedded librarian" term, 16 percent in the "digital learning objects" term, and 10 percent in the "synchronous ILI session" term. Use of these important databases was conspicuously absent in the terms with no dedicated ILI.

This finding suggests that the students using Web of Science and specialized anthropology databases as a result of dedicated ILI were more aware of the broader research landscape, more aware of what the research process entails, and willing to make additional effort to find sources. Precisely because Web of Science was included in the federated search tool, researchers expected at least some students in the nondedicated-ILI terms to have cited Web of Science sources, but none did. This finding suggests students in the "embedded librarian" term may have gone directly to Web of Science rather than encountering Web of Science sources via the federated search. More definitive, though, is that students' use of a specialized database not included in the federated search tool meant they sought out that resource intentionally. They accessed the database either through the subject guide or through the alphabetical list of databases. Implicit in this behavior is the awareness that the database or subject guide existed and that the student had a desire to use it.

Furthermore, every student who cited a specialized anthropology database also cited sources from the federated search, which means they searched for sources using at least two different resources. To put it in terms of metacognition, or, in ACRL Framework terms, "critical self-reflection," 53 students seemed aware of the choices available to them and were actively making choices. This research behavior means not only that the students knew about the resources but that they were willing to make the effort to search more than one. Implicit in this effort is an understanding of the expectation that the research process includes searching multiple databases and/or a sense that searching multiple databases was important enough to warrant the extra effort. Students may have felt that better supporting their topics was important enough to warrant consulting multiple databases.

The idea that better supporting topics drove students' search behavior in the "embedded librarian," "digital learning objects," and "synchronous ILI session" terms is in keeping with findings that most students' bibliographies from these terms exceeded the required minimum number of sources and that the sources students chose often exceeded the instructor's expectations for topic and course level. These students appear to have been aware of the importance of the bibliography in supporting their topics, and they were aware enough of the tools available to them-and aware at the right point in the term - that by the time they started their final research project, they were able to create more robust bibliographies.

\section{Discussion}

Both curricular and format differences between the modes of ILI correlated with differences in students' participation, engagement with active learning, and ultimately their selection of sources. Compared to the "taught as usual" term, the "curriculum scaffolding" (Fall 2016) mode of ILI focused increased attention on sources by requiring students to find an additional source on their own for the Reading Review assignments, and it increased attention on the bibliography with the introduction of the preliminary bibliography assignment; correspondingly, students' bibliographies got longer that term and better met the instructor's expectations.

However, students in the "curriculum scaffolding" term cited far fewer advanced sources than students in later terms with more dedicated ILI. The "curriculum scaffolding" mode gave 
students early and regular practice finding sources on their own, but, unlike the "embedded librarian," "digital learning objects," and "synchronous ILI" terms, it did not include an introduction to the broader landscape of available databases or to expectations surrounding the research process. Thus, students may not have known where to look beyond the library homepage, and they may not have known to experiment with search terms and databases. In other words, students in the "curriculum scaffolding" term may simply not have encountered sources that would fall in the advanced category and/or they may not have been as inclined to tackle difficult vernacular or more challenging concepts because they were not as motivated by an understanding of the significance of sources to supporting their topics.

In contrast, if students in the "embedded librarian" term (Winter 2017) acquired the skills the mode of ILI was intended to impart, they would have had fewer skills to assimilate at the point they began their final research projects and thus would have had more time for evaluating sources. Going into their final research projects, they would have better understood the significance of the bibliography and may have been more inclined to evaluate challenging sources and include them.

To these ends, the "embedded librarian" mode built on the "curriculum scaffolding" assignments and added two required interactions with the librarian, in which she provided dedicated ILI. The librarian specifically introduced each student to particular databases that would help them with that particular course and with their particular topics, pointed them to the archaeology subject guide, and laid out expectations about what the research process involves, such as experimenting with search terms and trying a range of databases. Adding nuance to Alverson's findings that, under a "high-touch" embedded librarian mode of ILI, students' work in an online college course produced bibliographies that better aligned with the instructor's expectations by having "enough sources," "enough scholarly material," and including sources that came from the library, ${ }^{54}$ students in the "embedded librarian" term of the current study regularly exceeded the minimum number of sources, exceeded the instructor's expectations with respect to quality, and made use of multiple databases including the databases most suited to their topics.

Aiming for the results of the "embedded librarian" term, the "digital learning objects" and "synchronous ILI" modes used exactly the same scaffolded curriculum and assignment structure but took a lower-touch (to play on Alverson's term, "high-touch" 55 ) approach to introducing students to the broader landscape of available databases and to expectations surrounding the research process. The lower-touch approach meant losing the one-on-one work the "embedded librarian" mode facilitated. Thus, also lost were instruction customized for each student's particular understanding of research, instruction customized for each student's specific topic, and the kinds of personal accountability that come with one-oneone communication. These missing aspects could explain why, compared to students in the "embedded librarian" term, students in the less interactive "digital learning objects" and "synchronous ILI" sections cited far fewer advanced sources and far fewer sources from the Web of Science or anthropology databases not included in the federated search function of the library's discovery tool.

Students' participation in ILI differed under the different instruction modes and could also help explain variations in students' search behavior and selection of sources from term to term. The differences in participation seem related to whether students were held accountable for their ILI work and related to the format of the ILI itself. Only one person made use of the 
optional librarian's D2L discussion thread in the "curriculum scaffolding" term (Fall 2016). In contrast, ILI in the "embedded librarian" term was part of a graded assignment and was itself worth 25 percent of the total assignment grade. The instructor reported that making students accountable for working with a librarian (grading it) "changed everything." Every student ended up participating in the "embedded librarian" ILI (in other words, every student asked the librarian at least one question), and those participating in the study (83.3\%) completed the assignments. This finding underscores Parramore's point that simply including ILI in an online environment does not ensure that it facilitates active learning. ${ }^{56}$ Making students accountable for their work is an aspect of engaging them in ILI, and grading is one way to make students accountable for their work.

With respect to the more sustainable modes of ILI, over 15 percent more students participated in the "digital learning objects" mode of ILI than participated in the synchronous ILI sessions (75\% vs. 60\%). This difference may be related to the fact that students in the "digital learning objects" class received entirely asynchronous ILI in keeping with the format of the course, but students required to attend a synchronous ILI session in D2L may not have been prepared to attend a "live" session when they were expecting an asynchronous course. The "synchronous ILI" term involved three sessions held at three different times of day, and the instructor offered to help anyone who could not make one of those times; nevertheless, students may not have been in a position to have any live online interaction due to a number of circumstances, including, as Flaherty noted, lack of access to "a quiet space and computers with strong internet connections to thrive during live class meetings" or special learning needs that synchronous learning cannot always accommodate. ${ }^{57}$ Participation is an obvious key to learning (that is, students have to attend class and engage in order to learn). Thus, student participation is also key to effective instruction.

Effective instruction also facilitates active learning, and the "digital learning objects" mode of ILI facilitated more active learning than did the synchronous ILI session. Students in the "digital learning objects" class received 10 points only if they completed the exercise, and the librarian designed the exercise to require students to answer a question before it allowed them to move on to the next one. Furthermore, students knew that the instructor would be reviewing the exercise and assigning a grade. Thus, this assignment structure encouraged students to engage with the ILI videos and practice questions, and students were graded on having engaged; therefore, this mode of ILI encouraged active learning in a way that the live, online ILI session may not have. Students who were required to attend a live ILI session received 10 points just for attending, and they did not have to participate beyond logging in to get the points. Students may or may not have paid attention during the librarian's session, and social conventions, such as eye contact, which might obligate students to pay attention, were absent in these audio-only online contexts. This finding also supports Parramore's assertion that simply providing ILI online is not enough. ${ }^{58}$ The ILI needs to facilitate-potentially by mandating it-students' engagement.

The differences in curriculum, participation, and active learning could explain differences in students' search behavior and source selection under the different modes of ILI the researchers employed. Curriculum scaffolding, alone, did some important ILI work, but more dedicated ILI resulted in students searching iteratively, leveraging a broader range of databases, using more appropriate, subject-specific databases, and selecting sources that better met the instructor's expectations. While the unsustainable "embedded librarian" mode 
yielded the most promising results, results from the lower-touch "digital learning objects" and "synchronous ILI" modes were more comparable to the "embedded librarian" term than to terms without dedicated ILI. Ultimately, this study unearthed nuanced changes in student work in response to different modes of ILI. These nuanced results could inform the modes of ILI librarians and instructors choose to incorporate in asynchronous online courses and could serve as the focus of future research.

\section{Conclusion and Future Research}

This study offers nuanced insight into how students' coursework changed in response to different modes of ILI in asynchronous online courses. One limitation of this case study is that it addresses only the specific ways in which the researchers deployed these modes of ILI; curriculum scaffolding, embedded librarianship, digital learning objects, and even synchronous instruction can take many forms in addition to the ones the researchers employed here. Furthermore, the study was a case study using ethnographic analysis that leveraged these approaches to facilitate exploration, but these approaches do not facilitate making broadly definitive claims. Nevertheless, the findings point to modes of ILI that librarians and instructors can target as ideal, such as combining curriculum scaffolding with a dedicated mode of ILI, and modes they can employ when more limited ILI is the only possibility. (It is useful to note that anything developed for an asynchronous course context can also be used in a synchronous or face-to-face course but not the other way around.)

Future research could explore other renditions of curriculum scaffolding by building ILI into existing assignments such that, in addition to giving students practice finding sources early in the term, they are also guided to the broad landscape of databases as well as to expectations that the research process involves iterative searching using multiple resources and search terms. Future research could also build on this more exploratory study to look at the effects on students' coursework of more granular variables such as students' ages, the course discipline, or students' prior experience with ILI. In general, the aim of this exploratory study was to provide cues for future research about ways the modes of ILI described here facilitated active learning and correlations between the different modes of ILI and students' awareness of the broader research landscape, students' source-selection behavior, and alignment of students' source-selection with instructors' expectations. Future research can use these cues as a basis for developing new modes of ILI to explore or to home in on specifics to make more generalizable claims.

Such research can strategically inform the development of ILI pedagogy and curricula for asynchronous online courses. Findings from this and future studies can also inform the collaboration between librarians and teaching faculty. Understanding which modes of ILI work best in asynchronous course contexts allows librarians to know which ILI options to offer and what kinds of course access they might need to achieve different effects on students' work. Thus, the findings from this and future studies can benefit librarians, instructors, and students in their important work together.

\section{Acknowledgments}

The authors wish to thank Michelle Desilets, Patrick Fuller, and Kerry Wu for reading earlier versions of this manuscript. 


\section{APPENDIX A. Anthropology 366 \& 368 Assignments}

Anthro 366

\section{Assignment 1}

Flannery et al. 1967 reading review

25 points

\section{Due Monday, April 18 before 11:55p}

This reading is a discussion of the role played by the environment in the emergence of early agricultural economies in Mesoamerica.

Flannery, K., A. Kirkby, M. Kirkby and A. Williams

1967 "Farming systems and political growth in Ancient Oaxaca," Science, vol. 158, pp. 445-454.

Your essay for this week is a summary of the issues presented in this reading. Use these general questions to guide you in reading the article.

\section{Part 1: Introduction to the research}

Summarize the three hypotheses proposed by the authors to explain why complex societies arose in Mesoamerica (hint: for a general discussion of social complexity, see Toby Evans, pp. 19-28). How do the authors use the concept of "nuclear areas" in examining social complexity in Mesoamerica? What are the five nuclear areas identified by the authors as maintaining their political position from Archaic times (beginning $8000 \mathrm{BC}$ ) to Spanish conquest?

\section{Part 2: The Valley of Oaxaca}

Figure 4 (p. 448) illustrates a cross-section of the Valley of Oaxaca. Which environments do the authors consider advantageous for agriculture? Why do these areas offer advantages? How did the earliest occupants of the valley make a living (e.g. were they farmers, or did they forage?).

How does the Early Village Farming Period differ from the earlier Archaic period? What activities are initiated during this period that lead to the formation of "nuclear areas?"

\section{Part 3: Conclusions}

What do the authors conclude? What evidence do they describe that supports their conclusions? Your essay should be between 2-4 pages double-spaced. Essays should be submitted in *word* (.doc) or *rich text format* (.rtf). Do not submit PDFs. One easy way to create a word document is to use Google Docs on the Google Drive. To watch a brief video about how to use Google Docs, follow this link: https://youtu.be/LtngjgwNL2k

\section{Citation guidelines}

Follow these citation guidelines when citing information from the readings. Remember to include page numbers when quoting directly, or when closely summarizing the information in the article. Please include the complete text reference at the end of the paper.

Flannery, K., A. Kirkby, M. Kirkby and A. Williams 1967 "Farming systems and political growth in Ancient Oaxaca," Science, vol. 158, pp. 445-454.

When citing specific material or quoting from a reading, include the page number (Author date:pp), or (Flannery et al. 1967:445). 


\section{Grading rubric}

25-22 points

Content: Student is able to clearly and comprehensively summarize what the authors are attempting to demonstrate within the context of the provided background material.

Organization: Student organizes the essay in a clear and logical manner using paragraphs that follow a logical progression. Essay starts with an introductory overview paragraph followed by logically sequenced paragraphs that flesh out the ideas in the introductory paragraph. Essay ends with a concluding paragraph summarizing the information presented and how it bears on larger issues.

Spelling and grammar: Spelling and grammatical errors are minimal to non-existent. Sentences are clear and neither overly long or incomplete. Student follows proper citation guidelines.

21-18 points

Content: Student understands what the authors are attempting to demonstrate, but leaves some terms undefined and some background information is omitted.

Organization: Essay construction may not follow a logical progression. Paragraphs may not be comprised of a single idea that fleshes out the information in the introductory paragraph. Essay may not end with a summary concluding paragraph.

Spelling and grammar: Some spelling and grammatical errors are present. Some sentences are difficult to follow, are incomplete or overly long. Student attempts to follow proper citation guidelines.

\section{7-14 points}

Content: Student may not understand what the authors are attempting to demonstrate, leaves terms undefined and omits important background information.

Organization: Paragraph structure is not used, essay construction does not follow a logical progression. Essay does not end with a summary concluding paragraph.

Spelling and grammar: Abundant spelling and grammatical errors are present. Sentences are difficult to follow. Student does not follow proper citation guidelines.

Less than 14 points ...

As with the 17-14 point range, only more so... 
Anthro 366

\section{Assignment 2}

25 points

Due Monday, May 9 before 11:55p

Reading

Heyden, Doris

1975 "An Interpretation of the Cave underneath the Pyramid of the Sun in Teotihuacan, Mexico," American Antiquity, vol. 40, pp. 131-147.

Note: This reading is linked to the "Week 6" content module. Citation guidelines and a grading rubric are provided on pp. 2-3 of this assignment sheet.

This assignment relates to...

Learning outcome \#1: Heyden presents several hypotheses about the cave under the Pyramid of the Sun. You have an opportunity to evaluate her hypotheses against the evidence presented in the article.

Learning outcome \#2: In evaluating Heyden's hypotheses, you will see how archaeological conclusions are successfully or unsuccessfully linked to supporting evidence.

Your essay for this week is a summary of the issues presented in this paper. As before, to guide you in your summary, I have provided you a basic structure for summarizing the information from the reading. Use these general questions to guide you in reading the article. Your answers to these questions should be linked together to form an essay. Further information about organization and grading can be found in the "Grading Rubric" on the second page.

Your essay should be 3-4 pages long, double-spaced in Word or Rich Text Format (no PDFs or Pages files). When you refer to material in the reading, cite the page number where the material was taken (for example Heyden 1975:143) in the text. Include the complete bibliographic reference at the end of your paper.

\section{Part 1: Introduction to the research}

Summarize what Heyden is attempting to demonstrate by studying the cave under the Pyramid of the sun. What evidence does she present to suggest that the cave was a cult center before the construction of the Pyramid of the Sun?

\section{Part 2: Significance of caves in Mesoamerica}

Summarize the author's overview of the significance of caves in Mesoamerica (pp. 134-138). What is the nature of the evidence she presents? Is it empirical (material)? Or is it anecdotal (based on retelling of stories)? Or both?

What aspects of the cave at Teotihuacan can be related to the general significance of caves in Mesoamerica (pp. 139-143).

\section{Part 3: Conclusions and evaluation}

What does Heyden conclude with regard to the cave under the Pyramid of the Sun being a cult center? Of the nine possibilities she presents, can any be empirically verified? 
Your opinion: Has the information Heyden presented persuaded you that the cave under the Pyramid of the Sun was an ancient cult center? Why or why not?

\section{Citation guidelines}

Follow these guidelines when citing information from the readings. When you refer material in the reading in the body of your essay, cite the (Author date:page number) from where the material was taken (for example Heyden 1975:133) in the text. Include the complete bibliographic reference at the end of your paper.

Heyden, Doris

1975 "An Interpretation of the Cave underneath the Pyramid of the Sun in Teotihuacan, Mexico," American Antiquity, vol. 40, pp. 131-147.

\section{Grading rubric}

25-22 points

Content: Student is able to clearly and comprehensively summarize what the authors are attempting to demonstrate within the context of the provided background material.

Organization: Student organizes the essay in a clear and logical manner using paragraphs that follow a logical progression. Essay starts with an introductory overview paragraph followed by logically sequenced paragraphs that flesh out the ideas in the introductory paragraph. Essay ends with a concluding paragraph summarizing the information presented and how it bears on larger issues.

Spelling and grammar: Spelling and grammatical errors are minimal to nonexistent. Sentences are clear and neither overly long or incomplete. Student follows proper citation guidelines.

21-18 points

Content: Student understands what the authors are attempting to demonstrate, but leaves some terms undefined and some background information is omitted.

Organization: Essay construction may not follow a logical progression. Paragraphs may not be comprised of a single idea that fleshes out the information in the introductory paragraph. Essay may not end with a summary concluding paragraph.

Spelling and grammar: Some spelling and grammatical errors are present. Some sentences are difficult to follow, are incomplete or overly long. Student attempts to follow proper citation guidelines.

17-14 points

Content: Student may not understand what the authors are attempting to demonstrate, leaves terms undefined and omits important background information.

Organization: Paragraph structure is not used, essay construction does not follow a logical progression. Essay does not end with a summary concluding paragraph.

Spelling and grammar: Abundant spelling and grammatical errors are present. Sentences are difficult to follow. Student does not follow proper citation guidelines.

Less than 14 points ...

As with the 17-14 point range, only more so... 
Anthro 368

\section{Assignment 1}

Matisoo-Smith 2015 reading essay

25 points

\section{Due Monday, April 11 before 11:55p}

For this week, we are considering the initial peopling of Near Oceania and Australia. Austronesians are genetically distinct from other Asian populations, and the readings assigned here explain why that may be so.

\section{Readings}

Matisoo-Smith, E.

2015 "Ancient DNA and the Human Settlement of the Pacific: A Review," Journal of Human Evolution, vol. 79, pp. 93-104.

Wenz, J.

2014 "The Other Neanderthal," The Atlantic, http://www.theatlantic.com/technology/archive/2014/08/the-other-neanderthal/375916/. Retrieved April 3, 2016.

You have been provided links to these readings in the "Assignment 1" readings module in Week 2 in D2L. Citation guidelines and grading rubric are provided on pp. 2-3 of this assignment sheet.

Note: The Matisoo-Smith 2015 reading covers the entire span of the Pacific and the population of the expanse of the Pacific islands; for this assignment, you only need to focus on the parts of the reading relating to Austronesians: pp. 93-96, and pp. 100-101 (we will revisit this reading over the course of the quarter).

This assignment relates to...

Learning outcome \#2: Ancient DNA in combination with archaeological evidence illustrate interactions between early modern human populations as our earliest ancestors migrated out of Africa.

Essay

I have provided a list of questions for you to answer from the readings. A good essay will combine your answers to these questions into logically linked paragraphs.

1. Who were the Denisovans (see Wenz 2014)? What evidence exists of them?

2. What is the "Sahul"? What did the ancient Austronesians have to overcome to colonize this landmass and when did they do so (see Matisoo-Smith 2015)?

3. How do Austronesians compare with mainland Asians in terms of Denisovan DNA contribution (see Wenz 2014)?

4. Generally, what conclusions can be drawn about the timing of the earliest migrations into the Sahul from the genetics of Austronesians (see Matisoo-Smith 2015)?

Your essay should be between 2-4 double-spaced pages. Please submit your answers to the assignment dropbox in either *Word* or *Rich Text Format* Do not submit PDFs or "pages" files. I cannot comment on PDFs and I cannot open "pages" files. Please contact me if Word or Rich Text are problematic for you. 


\section{Citation guidelines}

Follow the Anthropology dept. guidelines (linked to the syllabus) when citing information from the readings. Remember to include page numbers when quoting directly, or when closely summarizing the information in the article. Please include the complete text reference at the end of the paper. Matisoo-Smith, E.

2015 "Ancient DNA and the Human Settlement of the Pacific: A Review," Journal of Human Evolution, vol. 79, pp. 93-104.

Wenz, J.

2014 "The Other Neanderthal," The Atlantic, http://www.theatlantic.com/technology/archive/2014/08/the-other-neanderthal/375916/. Retrieved April 3, 2016.

When citing specific material or quoting from a reading, include the page number (Author date:pp), or (Matisoo-Smith 2015:93). In the case of the website, the author and date is adequate (Wenze 2014).

\section{Grading rubric}

25-22 points

Content: Student is able to clearly and comprehensively summarize what the authors are attempting to demonstrate within the context of the provided background material.

Organization: Student organizes the essay in a clear and logical manner using paragraphs that follow a logical progression. Essay starts with an introductory overview paragraph followed by logically sequenced paragraphs that flesh out the ideas in the introductory paragraph. Essay ends with a concluding paragraph summarizing the information presented and how it bears on larger issues.

Spelling and grammar: Spelling and grammatical errors are minimal to non-existent. Sentences are clear and neither overly long nor incomplete. Student follows proper citation guidelines.

21-18 points

Content: Student understands what the authors are attempting to demonstrate, but leaves some terms undefined and some background information is omitted.

Organization: Essay construction may not follow a logical progression. Paragraphs may not be comprised of a single idea that fleshes out the information in the introductory paragraph. Essay may not end with a summary concluding paragraph.

Spelling and grammar: Some spelling and grammatical errors are present. Some sentences are difficult to follow, are incomplete or overly long. Student attempts to follow proper citation guidelines.

17-14 points

Content: Student may not understand what the authors are attempting to demonstrate, leaves terms undefined and omits important background information.

Organization: Paragraph structure is not used, essay construction does not follow a logical progression. Essay does not end with a summary concluding paragraph.

Spelling and grammar: Abundant spelling and grammatical errors are present. Sentences are difficult to follow. Student does not follow proper citation guidelines.

Less than 14 points

As with the 17-14 point range, only more so... 
Anthro 368

\section{Assignment 2}

Green and Weisler 2004

Lipo et al. 2013

\section{Due Monday, May 23 before 11:55p}

Environmental degradation has been tied to human activity and over-consumption in the islands of the far eastern Pacific (such as Jared Diamond's Collapse, 2005).

Jared Diamond on Easter Island: "(Easter Island is) the clearest example of a society that destroyed itself by over-exploiting its own resources," (through) "...a focus on statue construction and competition between clans and chiefs driving the erection of bigger statues requiring more wood, rope and food," (Diamond 2005:118-119).

Jared Diamond on Mangareva (and other Polynesian islands): "All over Polynesia, human settlement on islands that had developed for millions of years in the absence of humans led to habitat damage and mass extinctions of plants and animals" (Diamond 2005:132).

Diamond, J.

2005 Collapse: How societies choose to fail or succeed, New York: Viking Press.

Learning outcome \#1 and 2: Diamond's statements can be viewed as an hypothesis (a standard tool in scientific inquiry), that human overconsumption led to the degradation of ancient societies in the eastern Pacific. The readings for this assignment review archaeological evidence that bears on this hypothesis.

\section{Readings}

Green, R. and M. Weisler

2004 "Prehistoric introduction and extinction of animals in Mangareva, Southeast Polynesia," Archaeology of Oceania, vol. 39, pp. 34-41.

Lipo, C., T. Hunt and S. Haoa

2013 “The 'walking' megalithic statues of Easter Island," Journal of Archaeological Science, vol. 40, pp. 2859-2866.

Note: These readings are in the "Week 8" content module. For further information about statues on Rapa Nui, watch "The Lost Secret of Easter Island," a full-length documentary about statue building (also linked to "Week 8").

Your essay should be between 2-4 double-spaced pages. Please submit your answers to the assignment dropbox in either *Word* or *Rich Text Format* Do not submit PDFs or "pages" files. I cannot comment on PDFs and I cannot open "pages" files. Please contact me if Word or Rich Text are problematic for you, files in these formats can be created using "Google Docs." Essay and citation guidelines, and a grading rubric are provided on pp. 2-3 of this assignment sheet.

This week's essay has three parts.

\section{Part I: Introduction}

What do Lipo et al. 2012 set out to demonstrate? Why does this have implications for deforestation of Easter Island? What do Green and Weisler set out to demonstrate? Why does this have implications for human predation as the cause of environmental collapse? 


\section{Part II: Data}

Summarize the data used in both papers to test their hypotheses.

\section{Part III: Conclusions}

What do the authors of both papers conclude with regard to explaining depopulation in these remote islands?

\section{Citation guidelines}

Follow these guidelines when citing information from the readings. Remember to include page numbers when quoting directly, or when closely summarizing the information in the article. Please include the complete text reference at the end of the paper.

Green, R. and M. Weisler

2004 "Prehistoric introduction and extinction of animals in Mangareva, Southeast Polynesia," Archaeology of Oceania, vol. 39, pp. 34-41.

When citing specific material or quoting from a reading, include the page number (Author date:pp), or (Green and Weisler 2004:38).

\section{Grading rubric}

25-22 points

Content: Student is able to clearly and comprehensively summarize what the authors are attempting to demonstrate within the context of the provided background material.

Organization: Student organizes the essay in a clear and logical manner using paragraphs that follow a logical progression. Essay starts with an introductory overview paragraph followed by logically sequenced paragraphs that flesh out the ideas in the introductory paragraph. Essay ends with a concluding paragraph summarizing the information presented and how it bears on larger issues. Spelling and grammar: Spelling and grammatical errors are minimal to nonexistent. Sentences are clear and neither overly long nor incomplete. Student follows proper citation guidelines.

21-18 points

Content: Student understands what the authors are attempting to demonstrate, but leaves some terms undefined and some background information is omitted.

Organization: Essay construction may not follow a logical progression. Paragraphs may not be composed of a single idea that fleshes out the information in the introductory paragraph. Essay may not end with a summary concluding paragraph.

Spelling and grammar: Some spelling and grammatical errors are present. Some sentences are difficult to follow, are incomplete or overly long. Student attempts to follow proper citation guidelines.

17-14 points

Content: Student may not understand what the authors are attempting to demonstrate, leaves terms undefined and omits important background information.

Organization: Paragraph structure is not used, essay construction does not follow a logical progression. Essay does not end with a summary concluding paragraph.

Spelling and grammar: Abundant spelling and grammatical errors are present. Sentences are difficult to follow. Student does not follow proper citation guidelines.

Less than 14 points

As with the 17-14 point range, only more so... 
Anthro 366

\section{Final Project Guidelines}

65 points

\section{Research project goals}

For this project, you will need to find an archaeological journal article that describes / discusses a particular site, finding, or concept relevant to Mesoamerican archaeology.

Your job is to describe how the authors have come to their conclusions and whether the techniques they applied have provided empirical (real-world support) for their discovery.

You should use the library's online search features to find an article from an online journal that meets the following criteria:

1. The article should be about a specific archaeological study in Mesoamerica from any time period. The articles assigned for the class reading reviews are good examples (but these should not be used for your final project).

2. The article should be from an online journal from library holdings. Use the library DIY guides to help you locate an appropriate article from the library's online journal collection.

Content: Your project is a kind of extended reading review, similar to the two reading assignments. Your project should have the following components...

1. Background: Summarize the author(s)'s goals (review the article abstract). Provide a map showing the area of interest, if relevant.

2. Evidence: What kinds of archaeological materials, contexts, or other phenomena are of interest?

3. Methods of analysis: Provide some general information about the methods used, such as radiocarbon dating, stratigraphy, artifact analysis, or linguistic translation.

Do some background research on the methods - for example, a brief overview of radiocarbon dating (if relevant), or a brief discussion of excavation techniques - beyond what is discussed in the article.

4. Conclusions: Comment on the relationship between the conclusions and the methods and data used to reach them.

Format: You have a choice of format. You can either a) construct as a 20-25-slide PowerPoint presentation (or some equivalent) that is due Tuesday, May 31 or b) submit as a 6-8 page research paper that is due Monday, June 6.

If you choose to use PowerPoint to construct your presentation, your presentation will be posted online for student questions and comments. You may use a combination of slides with illustrations and text, or narration, if you choose. PowerPoint presentations will be eligible for extra credit because of the earlier due date. 
You should use the citation format specified in the tips for writing in Anthropology for any material you reference in your presentation.

Grading: Your grade will be based on...

Content: 40 points. This grade will be based on the quality of the information you present, background discussion, methods summary, and how well you relate your conclusions to the information you present.

Style: 15 points. This grade will be based on the quality of visual presentation (presentation option) or quality of written work (paper option). For example, were your pictures clear? Were there a lot of misspellings and ungrammatical sentences? How was the presentation/ paper organized; did one slide/ paragraph follow logically from the next? Is there an introduction and conclusion?

References: 10 points. This grade is based on the quality of your bibliography. Did you use library resources (including electronic journals you accessed online)? Did you find additional background information about the methods used in the article you selected? 
Anthro 368

\section{Final Project Guidelines}

65 points

\section{Research project goals}

For this project, you will need to find an archaeological journal article that describes / discusses a particular site, finding, or concept relevant to archaeology in Oceania.

Your job is to describe how the authors have come to their conclusions and whether the techniques they applied have provided empirical (real-world support) for their discovery.

You should use the library's online search features to find an article from an online journal that meets the following criteria:

1. The article should be about a specific archaeological study in Oceania from any time period. The articles assigned for the class reading reviews are good examples (but these should not be used for your final project).

2. The article should be from an online journal from library holdings. Use the library DIY guides to help you locate an appropriate article from the library's online journal collection.

Content: Your project is a kind of extended reading review, similar to the two reading assignments. Your project should have the following components...

1. Background: Summarize the author(s)'s goals (review the article abstract). Provide a map showing the area of interest, if relevant.

2. Evidence: What kinds of archaeological materials, contexts, or other phenomena are of interest?

3. Methods of analysis: Provide some general information about the methods used, such as radiocarbon dating, stratigraphy, artifact analysis, or linguistic translation.

Do some background research on the methods - for example, a brief overview of radiocarbon dating (if relevant), or a brief discussion of excavation techniques - beyond what is discussed in the article.

4. Conclusions: Comment on the relationship between the conclusions and the methods and data used to reach them.

Format: You have a choice of format. You can either a) construct as a 20-25-slide PowerPoint presentation (or some equivalent) that is due Tuesday, May 31 or b) submit as a 6-8 page research paper that is due Monday, June 6.

If you choose to use PowerPoint to construct your presentation, your presentation will be posted online for student questions and comments. You may use a combination of slides with illustrations and text, or narration, if you choose. PowerPoint presentations will be eligible for extra credit because of the earlier due date. 
You should use the citation format specified in the tips for writing in Anthropology for any material you reference in your presentation.

Grading: Your grade will be based on...

Content: 40 points. This grade will be based on the quality of the information you present, background discussion, methods summary, and how well you relate your conclusions to the information you present.

Style: 15 points. This grade will be based on the quality of visual presentation (presentation option) or quality of written work (paper option). For example, were your pictures clear? Were there a lot of misspellings and ungrammatical sentences? How was the presentation/ paper organized; did one slide/ paragraph follow logically from the next? Is there an introduction and conclusion?

References: 10 points. This grade is based on the quality of your bibliography. Did you use library resources (including electronic journals you accessed online)? Did you find additional background information about the methods used in the article you selected? 


\section{APPENDIX B. Anthropology 366 \& 368 Preliminary Bibliography Assignment}

Project Bibliographies

Due November 14, 2016, 11:55 PM

Please review the Final project guidelines. For this week, you are required to submit a preliminary project bibliography, due Monday, November 14 before 11:55p.

Your preliminary project bibliography should consist of a list of three references. One of these should be the article you plan to use for your final project. The other two should be supplemental references to which you will refer to support and elaborate on the information in your main article.

Please upload your reference list, formatted in using the style specified in the "Guide to Writing Anthropology."

A sample presentation is posted in the "Syllabus and Schedule" module. 
APPENDIX C: Anthropology 368 ILI Tutorial

Qualtrics Survey Software

\section{Block 4}

\section{Name}

Default Question Block

To answer the next questions, please watch the video.

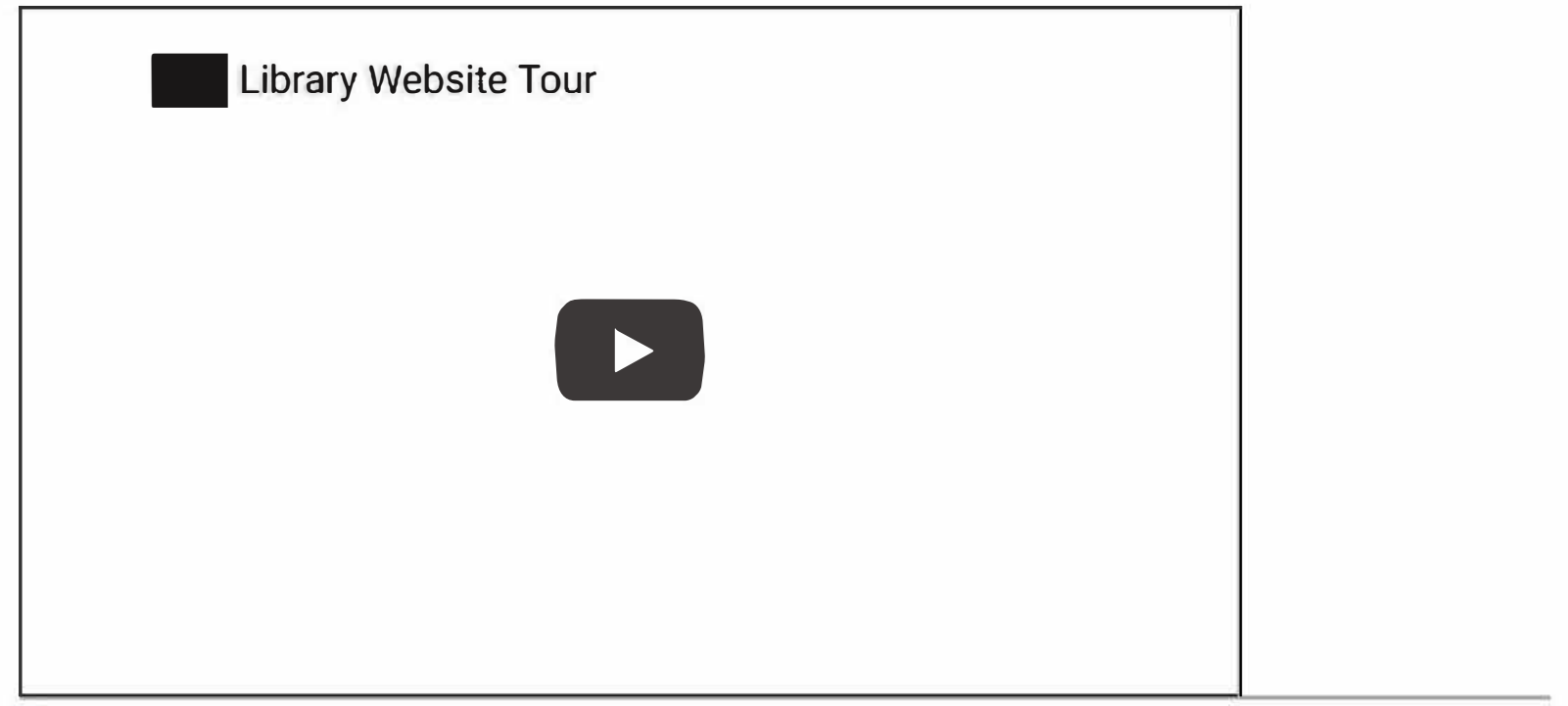

List three ways you can contact a librarian from off-campus.

1.

2.

3.

Block 2

To answer the next questions, please watch the video. 


\section{Brainstorming Keywords}

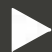

Think about the words you will use to search for articles and books on your topic. Then, think about some possible synonyms or related terms, e.g., for "agriculture," you could try agricultural, farm, farms, farmed, or farming. For "pottery," you could try: ceramic, sherd, or vessel.

For historic locations, such as "ancient Mexico," you could try: Yucatan or Mesoamerica.

List two possible synonyms or related terms you could use instead of "Egypt:"

1.

2.

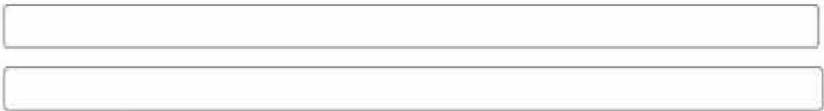

List two possible synonyms or related terms you could use instead of "pyramid:"

1.

2.

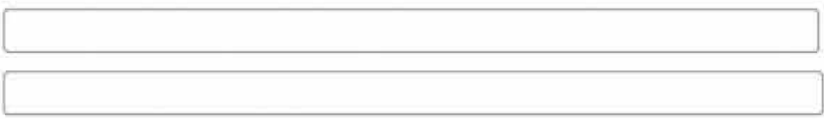

List two possible synonyms or related terms you could use instead of "stone:"

1.

2.

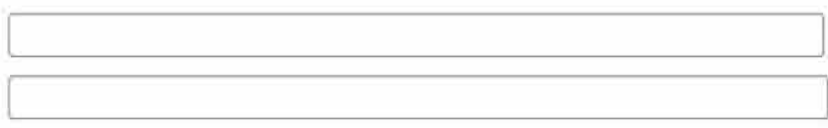


Qualtrics Survey Software

\section{Block 3}

To answer the next questions, please watch the video, then also look at the library website.

Using a Library Database to Find Articles

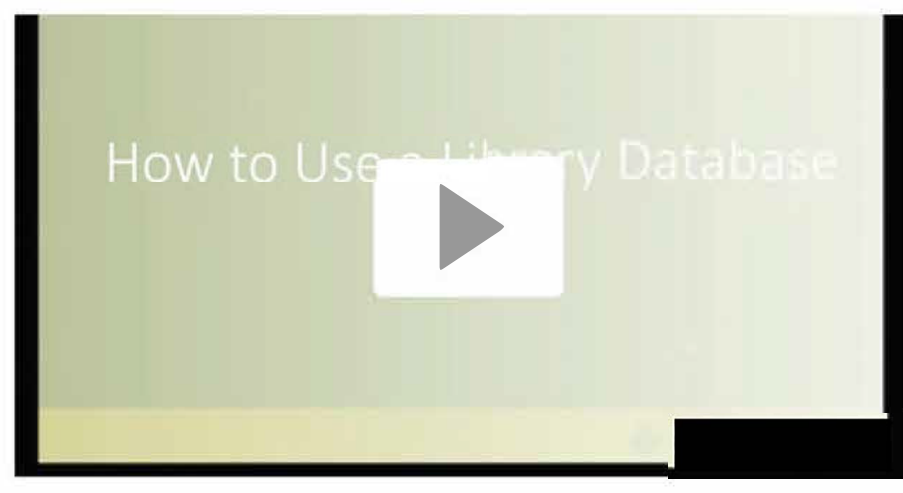
$>470: 00 / 7: 23$
CC $1 x$ AD

Go to the library website. Find an article for which the full text is available. Then fill out the information below.

Article title
Journal title
Article date
Author
Database used to find article

For your course, the librarian recommends starting with the databases: Web of Science and Anthropology Plus. Look at the Library archaeology subject guide, and list three other databases that cover archaeology articles:
1.
2.
3.

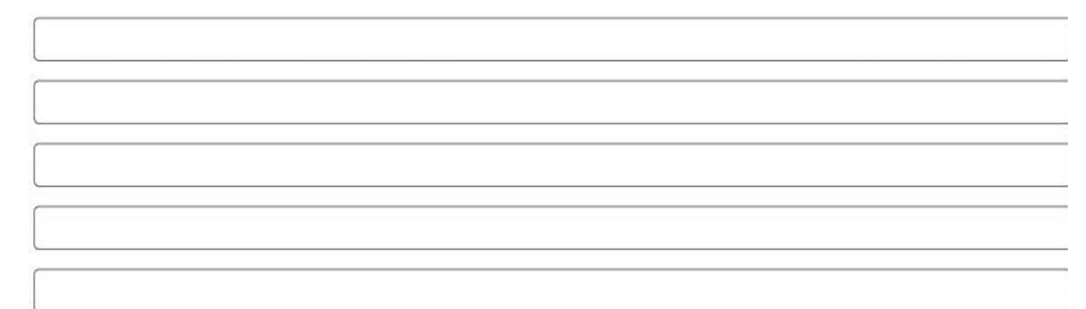

Which service could you use to get an article the library does not have?

Grab 'N Go (GNG)

Interlibrary Loan (ILL)

Mobile Information, Etc. (MBE) 


\section{Block 3}

To answer the next questions, please watch the video, then also look at the library website.

How to Get a Book

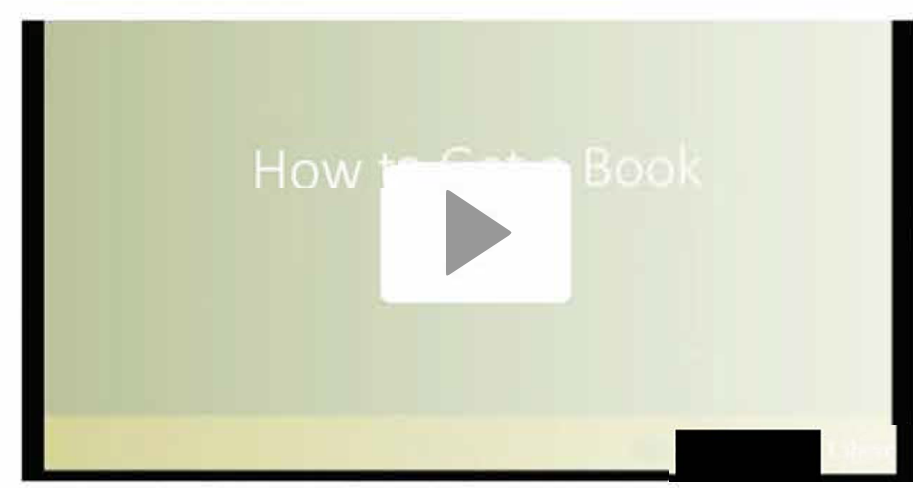
4. $0: 00 / 4: 31$
(C) $1 x$ (AD) next

Using the library website, find an ebook the library has. Then fill out the information below

Book title

Author

Publisher

Using the library website, find a print book the library has. Then fill out the information below

Book title

Author

Publisher

How far from campus do online-only students have to live to qualify for home delivery of books?
$\bigcirc$ at least 10 miles
at least 20 miles
at least 30 miles
$\bigcirc$ at least 40 miles 


\section{Notes}

1. Babson Survey Research Group, "Grade Increase: Tracking Distance Education in the United States" (2018), https://www.onlinelearningsurvey.com/highered.html.

2. National Center for Education Statistics, "Number and Percentage Distribution of Students Enrolled at Title IV Institutions, by Control of Institution, Student Level, Level of Institution, Distance Education Status of Student, and Distance Education Status of Institution: United States, Fall 2018," https://nces.ed.gov/ipeds [accessed 2 August 2020].

3. Office of the Registrar Portland State University, "Datamaster Report: Fully Online Courses 2015-2017" (PSU, 2017).

4. Colleen Flaherty, "Synchronous Instruction Is Hot Right Now, but Is It Sustainable?" Inside Higher Ed (April 29, 2020), https://www.insidehighered.com/news/2020/04/29/synchronous-instruction-hot-right-now-itsustainable\#.

5. Flaherty, "Synchronous Instruction Is Hot Right Now, but Is It Sustainable?"

6. Flaherty, "Synchronous Instruction Is Hot Right Now, but Is It Sustainable?"

7. Starr Hoffman and Lilly Ramin, "Best Practices for Librarians Embedded in Online Courses," Public Services Quarterly 6, no. 2/3 (April 2010): 292-305.

8. Hoffman and Ramin, “Best Practices for Libraries Embedded in Online Courses," 196.

9. Scott Spangler, Dana Casper, and Deborah Stanfield, "Online Students' Perceptions of Embedded Librarians: A Pilot Study," Issues in Information Systems 21, no. 1 (2020): 167-76.

10. Jessica Alverson, Jennifer Schwartz, and Sue Shultz, "Authentic Assessment of Student Learning in an Online Class: Implications for Embedded Practice," College \& Research Libraries 80, no. 1 (2019): 32-43.

11. Spangler, Casper, and Stanfield, "Online Students' Perceptions of Embedded Librarians," 167-76.

12. Alverson, Schwartz, and Shultz, "Authentic Assessment of Student Learning in an Online Class."

13. Leticia Camacho, "If We Built It, Would They Come? Creating Instruction Videos with Promotion in Mind," Journal of Business \& Finance Librarianship 23, no. 1 (January 2018): 26-34.

14. Liz Thompson and Howard S. Carrier, "Scalable Equals Asynchronous and Asynchronous Equals Boring; or Does It?" Internet Reference Services Quarterly. 21, no. 3/4 (July 2016): 81.

15. Ashley Lierman and Ariana Santiago, "Developing Online Instruction According to Best Practices," Journal of Information Literacy 13, no. 2 (December 2019): 206-21.

16. Nancy Dewald et al., "Information Literacy at a Distance: Instructional Design Issues," Journal of Academic Librarianship 26, no. 1 (2000): 33-44.

17. John R. Savery, "Overview of Problem-Based Learning: Definitions and Distinctions," Interdisciplinary Journal of Problem-Based Learning 1, no. 1 (2006).

18. A Taxonomy for Learning, Teaching, and Assessing: A Revision of Bloom's Taxonomy of Educational Objectives, eds. Lorin Anderson and David Krathwohl (New York, NY: Longman, 2001).

19. American Library Association, "Framework for Information Literacy for Higher Education" (February 9, 2015), www.ala.org/acrl/standards/ilframework.

20. Lierman and Santiago, "Developing Online Instruction According to Best Practices," 207.

21. Sarah Parramore, "Online Active-Learning: Information Literacy Instruction for Graduate Students," Reference Services Review: RSR 47, no. 4 (2019): 478.

22. Anastasia Misseyanni, "Introduction," in Active Learning Strategies in Higher Education: Teaching for Leadership, Innovation, and Creativity, eds. Anastasia Misseyanni et al. (Bingley, UK: Emerald Publishing, 2018), 1-16.

23. Lorayne Robertson, "Chapter 1: Toward an Epistemology of Active Learning in Higher Education and Its Promise," in Active Learning Strategies in Higher Education: Teaching for Leadership, Innovation, and Creativity, eds. Anastasia Misseyanni et al. (Bingley, UK: Emerald Publishing, 2018), 17-44.

24. Parramore, "Online Active-Learning." 17.

25. Robertson, "Chapter 1: Toward an Epistemology of Active Learning in Higher Education and Its Promise,"

26. William H. Walters et al., "A Multi-Method Information Literacy Assessment Program: Foundation and Early Results," portal: Libraries and the Academy 20, no. 1 (2020): 101-35.

27. Walters et al., "A Multi-Method Information Literary Assessment Program," 106.

28. Walters et al., "A Multi-Method Information Literary Assessment Program," 103.

29. Walters et al., "A Multi-Method Information Literary Assessment Program," 103.

30. Camacho, "If We Built It, Would They Come?"

31. Thompson and Carrier, "Scalable Equals Asynchronous and Asynchronous Equals Boring," 89.

32. Lierman and Santiago, "Developing Online Instruction According to Best Practices," 216. 
33. Alverson, Schwartz, and Shultz, "Authentic Assessment of Student Learning in an Online Class."

34. Walters et al., "A Multi-Method Information Literacy Assessment Program," 116.

35. Bonnie Gratch, "Toward a Methodology for Evaluating Research Paper Bibliographies," Research Strategies 3, no. 4 (1985): 170-77.

36. Philip M. Davis, "The Effect of the Web on Undergraduate Citation Behavior: A 2000 Update," College $\mathcal{E}$ Research Libraries 63, no. 1 (2002); A.M. Robinson and K. Schlegl, "Student Bibliographies Improve When Professors Provide Enforceable Guidelines for Citations," portal: Libraries and the Academy 4, no. 2 (2004): 275-90; Anne Middleton, "An Attempt to Quantify the Quality of Student Bibliographies," Performance Measurement and Metrics 6, no. 1 (2005): 7-18; D.H. Mill, “Undergraduate Information Resource Choices," College \& Research Libraries 69, no. 4 (2008): 342-55.

37. Casey Long and Milind Shirkhande, "Using Citation Analysis to Evaluate and Improve Information Literacy Instruction," in Collaborative Information Literacy Assessments: Strategies for Evaluating Teaching and Learning, Information Literacy Sourcebooks (New York, NY: Neal-Schuman Publishers, Inc., 2010); Thomas L. Reinsfelder, "Citation Analysis as a Tool to Measure the Impact of Individual Research Consultations," College E Research Libraries 73, no. 3 (2012).

38. Maria Elizabeth Clarke and Charles Oppenheim, "Citation Behaviour of Information Science Students II: Postgraduate Students," Education for Information 24, no. 1 (2006).

39. Long and Shirkhande, "Using Citation Analysis to Evaluate and Improve Information Literacy Instruction."

40. Clarke and Oppenheim, "Citation Behaviour of Information Science Students II: Postgraduate Students"; Mill, “Undergraduate Information Resource Choices."

41. Long and Shirkhande, "Using Citation Analysis to Evaluate and Improve Information Literacy Instruction."

42. Reinsfelder, "Citation Analysis as a Tool to Measure the Impact of Individual Research Consultations"; Long and Shirkhande, "Using Citation Analysis to Evaluate and Improve Information Literacy Instruction."

43. Clarke and Oppenheim, "Citation Behaviour of Information Science Students II: Postgraduate Students"; Mill, "Undergraduate Information Resource Choices"; Reinsfelder, "Citation Analysis as a Tool to Measure the Impact of Individual Research Consultations."

44. Chris Leeder, Karen Markey, and Elizabeth Yakel, "A Faceted Taxonomy for Rating Student Bibliographies in an Online Information Literacy Game," College \& Research Libraries 73, no. 2 (2012): 115-33.

45. Sarah P.C. Dahlen and Kathlene Hanson, "Preference vs. Authority: A Comparison of Student Searching in a Subject-Specific Indexing and Abstracting Database and a Customized Discovery Layer," College E Research Libraries 78, no. 7 (November 2017): 878-97.

46. Alverson, Schwartz, and Shultz, "Authentic Assessment of Student Learning in an Online Class."

47. Barney G. Glaser, Emergence vs Forcing: Basics of Grounded Theory Analysis (Mill Valley, CA: Sociology Press, 1992), 16.

48. Barney G. Glaser and Anselm Strauss, The Discovery of Grounded Theory: Strategies for Qualitative Research, (Hawthorne, NY: Aldine de Gruyter, 1967), 45.

49. Laura Nader, "Ethnography as Theory," HAU Journal of Ethnographic Theory 1, no. 1 (2011): 211.

50. Anthony Kwame Harrison, Ethnography (Oxford, UK: Oxford University Press), 118.

51. Harrison, Ethnography, 117.

52. Alverson, Schwartz, and Shultz, "Authentic Assessment of Student Learning in an Online Class."

53. American Library Association, "Framework for Information Literacy for Higher Education."

54. Alverson, Schwartz, and Shultz, "Authentic Assessment of Student Learning in an Online Class," 36-37.

55. Alverson, Schwartz, and Shultz, "Authentic Assessment of Student Learning in an Online Class," 36-37.

56. Parramore, "Online Active-Learning," 478.

57. Flaherty, "Synchronous Instruction Is Hot Right Now, but Is It Sustainable?"

58. Parramore, "Online Active-Learning," 478. 